\title{
Chromosome 9p21.3 polymorphism in a Chinese Han population is associated with angiographic coronary plaque progression in non-diabetic but not in type 2 diabetic patients
}

Wei Wang ${ }^{1,2+}$, Wenhui Peng ${ }^{2 \dagger}$, Xianling Zhang ${ }^{2 \dagger}$, Lin Lu ${ }^{1,2}$, Ruiyan Zhang ${ }^{1}$, Qi Zhang ${ }^{1}$, Lingjie Wang ${ }^{1,2}$, Qiujing Chen ${ }^{2}$, Weifeng Shen ${ }^{1,2^{*}}$

\begin{abstract}
Background: We sought to explore the association of variant rs1333049 on chromosome 9p21.3 with coronary artery disease (CAD) and angiographic plaque progression in non-diabetic and type 2 diabetic patients.

Methods: Genotyping and quantitative coronary angiography (QCA) were performed in 2046 Chinese Han patients (1012 diabetic cases) undergoing coronary angiography; 430 of them received repeat angiographic studies at 1 -year follow-up.

Results: CC genotype at rs1333049 on chromosome 9p21.3 was associated with CAD (unadjusted OR 1.524, $p=0.001$ and adjusted OR 1.859, $p=0.005$, respectively). However, CC genotype had no magnified association with $C A D$ in diabetic patients (OR 1.275, $p=0.150)$ compared with non-diabetic counterparts (OR 1.446, $p=0.020)$ after adjusting for conventional risk factors. During angiographic follow-up, non-diabetic patients $(n=280)$ had significant decrease in minimal lumen diameter and increase in percent diameter stenosis among the three genotypes ( $p=0.005$ and $p=0.038$, respectively), demonstrating that CC or GC genotype carriers had a more severe plaque progression than GG genotype carriers. In patients with type 2 diabetes $(n=150)$, although plaque progression was more severe than that in non-diabetic counterparts, no relations existed between plaque progression and genotypes. Rs 1333049 was an independent determinant of plaque progression for non-diabetic (OR 3.468, $p=0.004$ and OR 4.339, $p=0.002$ for GC and CC genotype, respectively) but not for diabetic patients (OR 0.529, $p=0.077$ and OR 0.878, $p=0.644$ for GC and CC genotype, respectively).
\end{abstract}

Conclusions: This study demonstrates a significant association of homozygous CC genotype of rs1333049 on chromosome 9p21.3 with CAD in Chinese Han population. Rs1333049 polymorphism is an independent determinant for coronary plaque progression in non-diabetic but not in type 2 diabetic patients.

\section{Background}

Recent genome-wide scanning has implicated chromosome 9 p21.3 as a novel locus conferring susceptibility to coronary artery disease (CAD), myocardial infarction and cardiac death [1-5], which is independent of traditional risk factors including gender, age, obesity, smoking, hypertension and hyperlipidemia [6,7]. Several

\footnotetext{
* Correspondence: rjshenweifeng@yahoo.com.cn

† Contributed equally

'Department of Cardiology, Rui Jin Hospital, Shanghai Jiaotong University

School of Medicine, Shanghai 200025, People's Republic of China

Full list of author information is available at the end of the article
}

studies showed that chromosome 9p21.3 was a vital genetic region with different independent loci of SNPs related to either diabetes or CAD [8-11]. The risk of CAD associated with 9 p21 variant was increased in the presence of poor glycemic control in type 2 diabetes [8]. Also, as one of the risk equivalents of CAD, patients with diabetes often had an increased atherosclerotic burden and inflammatory process in the coronary artery tree [12-14]. Thus, we hypothesized that certain locus on chromosome 9p21.3 might have its effect in a common pathway of diabetes and CAD. In a recent study, 
Chen et al revealed no association between coronary atherosclerotic plaque progression and polymorphism on chromosome 9p21.3 in Caucasian population [15]. Admittedly, this cross-section study was not designed to seek possible association of 9p21.3 with CAD in a special diabetic population. Furthermore, genetic effect of variant rs1333049 on chromosome 9p21.3 on angiographic coronary disease progression in Chinese patients remains unclear. Therefore, the present case-control study was conducted to examine whether this locus influences angiographic plaque progression in Chinese Han non-diabetic and type 2 diabetic patients.

\section{Methods}

\section{Patients}

The study protocol was approved by the hospital Ethics Committee, and written informed consents were obtained from all subjects.

The study population consisted of 2046 Chinese Han patients (1012 diabetic and 1034 non-diabetic cases) undergoing coronary angiography between March 2004 and December 2007 for the evaluation of suspected or established CAD (luminal diameter narrowing $250 \%$ ); 430 of them received repeat angiography at 1-year follow-up. Type 2 diabetes was defined as a fasting plasma glucose level $\geq 7.0 \mathrm{mmol} / \mathrm{L}$ or non-fasting plasma glucose level $\geq 11.1 \mathrm{mmol} / \mathrm{L}$, or taking oral hypoglycemic drugs or receiving parenteral insulin therapy. Patients with type 1 diabetes were excluded by measuring $C$ peptide, and excluded were also those with chronic viral or bacterial infection, tumor, or immune system disorders. Diagnosis of hypertension was based on the presence of elevated systolic $(\geq 140 \mathrm{mmHg})$ and/or diastolic $(\geq 90 \mathrm{mmHg})$ blood pressure, or current use of antihypertensive medications for one year before admission. Patients were diagnosed as hyperlipidemia if serum levels of total cholesterol (TC) $>5.7 \mathrm{mmol} / \mathrm{l}(220 \mathrm{mg} / \mathrm{dl})$, triglycerides $(\mathrm{TG})>1.7 \mathrm{mmol} / \mathrm{l}$ $(150 \mathrm{mg} / \mathrm{dl})$, low-density lipoprotein cholesterol (LDL-C) $>3.64 \mathrm{mmol} / \mathrm{L}(140 \mathrm{mg} / \mathrm{dl})$, or high-density lipoprotein cholesterol (HDL-C) $<0.91 \mathrm{mmol} / \mathrm{L}(35 \mathrm{mg} / \mathrm{dl})$.

\section{Coronary angiography and quantitative analysis}

Coronary angiography was performed using standard Judkins techniques or through radial approach, and all major coronary arteries were carefully imaged on at least two orthogonal views. Quantitative coronary analysis (QCA) was performed (TERRA, GE, USA) by two experienced interventional cardiologists, who were unaware of clinical information of the patients. For those with coronary angiography at baseline and 1-year follow-up, all coronary arteries intervened with percutaneous coronary intervention (PCI) were excluded to avoid inclusion of post-PCI neointimal hyperplasia or restenosis [16]. The coronary artery segments analyzed included all those plaques with a reference diameter $\geq 1.5 \mathrm{~mm}$ and a stenosis $\geq 20 \%$ at baseline and those with new lesions at follow-up in non-PCI intervened artery. Using the outer diameter of the contrast-filled catheter as the calibration, the minimal lumen diameter (MLD) in diastole was measured from multiple projections. Atherosclerotic plaque progression was diagnosed if one of the following criteria was met: $(1) \geq 10 \%$ diameter reduction of a pre-existing stenosis $\geq 50 \%$; (2) $\geq 30 \%$ diameter reduction of a stenosis $<50 \%$; (3) progression of any stenosis to total occlusion, or (4) development of a new stenosis $\geq 30 \%$ in a previously normal segment [17]. A new coronary lesion was defined as a stenosis that was not apparent on the initial angiogram or was $<20 \%$ in diameter stenosis but that narrowed by $\geq 0.4 \mathrm{~mm}$ in MLD at the follow-up angiogram [18]. Coronary artery score was calculated from per-patient average of the MLD of all the measured segments in observed coronary artery, and cumulative coronary obstruction was the sum of all percent diameter stenosis in standard index unit $(50 \%=0.50)$ [19]. Change of QCA measurements was defined as baseline QCA measurement minus follow-up measurement.

\section{Biochemical investigation}

Blood samples were collected after an overnight fasting in all patients and were stored at $-80^{\circ} \mathrm{C}$. Serum glucose, hemoglobin $\mathrm{A}_{1 \mathrm{c}}\left(\mathrm{HbA}_{1 \mathrm{c}}\right)$, insulin levels, blood urea nitrogen $(B U N)$, creatinine, and lipid profiles (TC,LDL-C, HDL-C,TG) were measured (HITACHI 912 Analyzer, Roche Diagnostics, Germany). Serum high sensitivity C-reactive protein (hsCRP) level was determined using a high-sensitivity ELISA kit (Biocheck Laboratories, Toledo, $\mathrm{OH}, \mathrm{USA}$ ) with a linear range of $0.62-119.3 \mathrm{mg} / \mathrm{L}$ and an inter-assay $\mathrm{CV}<7.5 \%$.

\section{Genotyping}

Genomic DNA was extracted from peripheral blood leucocytes by standard phenol-chloroform extraction. Genotyping was performed with TaqMan SNP allelic discrimination by means of an ABI 7900HT (Applied Biosystems, Foster City, CA, USA), in 384-well format. The TaqMan Assay kit was purchased from Applied Biosystems (Foster City, CA, USA). Genotypes were determined with the same method as previously described [20], in which primers of rs1333049 polymorphism were TCACTACCCTACTGTCATTCCTCAT and TTGCTTACCTCTGCGAGTGG, and probes were VIC-CAACAGTTCAAAAGCA and FAM-AACAGTTGAAAAGCA. Data were analyzed using the ABI Prism SDS software version 2.1.

\section{Statistical analysis}

Continuous variables are presented as mean \pm standard deviation, and categorical data are summarized as 
frequencies or percentages. Normal distribution of continuous variable was evaluated with Kolmolgorov-Smirnov test. For categorical variables, differences between groups were evaluated by the chi-square test. Differences among genotypes were analyzed by one-way analysis of variance (ANOVA) followed by post-hoc analysis (Bonferroni's correction) for comparison between groups. Odds ratios (ORs) of CAD were first estimated by chi-square test and then adjusted by traditional risk factors for CAD including gender, age, hypertension, hyperlipidemia, smoking status and diabetes (all factors with $p<0.05$ between CAD and non-CAD in the study population). ORs of covariates determining plaque progression were estimated using a multivariable logistic regression model. A 2-sided probability level of $\leq 0.05$ was considered significant. All analyses were done with SPSS for Windows 13.0 (SPSS Inc, Chicago, Illinois, USA).

\section{Results}

\section{Baseline characteristics of the study population}

As expected, patients with CAD were older and more male gender, and had more risk factors for CAD including smoking, hypertension, hyperlipidemia and diabetes and higher serum hsCRP level than those without CAD (all $p<0.05$; data not shown). Despite similar medical treatments, patients with plaque progression had more diabetes, elevated serum levels of $2 \mathrm{~h}$ plasma glucose and hsCRP, and reduced HDL-C than those without plaque progression (Table 1).

\section{Association between rs1333049 polymorphism and CAD} The genotype frequencies of rs1333049 were in HardyWeinberg equilibrium in patients with and without CAD (all $p>0.05$, data not shown). CC genotype of rs1333049 was associated with CAD in overall patients with unadjusted OR $1.524,95 \%$ CI 1.192-1.949, $p=0.001$ and adjusted OR $1.859,95 \%$ CI 1.212-2.852, $p=0.005$, respectively (Table 2 ). Further analysis showed that CC genotype was not significantly associated with CAD in diabetic patients (OR 1.275, 95\% CI 0.843-1.930, $p=0.150$ ) compared with non-diabetic counterparts (OR 1.446 95\% CI 1.145-1.826, $p=0.020$ ).

\section{Association between rs1333049 polymorphism and plaque progression}

Biochemical measurements and angiographic features with respect to various genotypes are listed in Table 3. White blood cell (WBC) and neutrophile counts were significantly higher in CC genotype carriers. There were no significant differences in changes of MLD, percent diameter stenosis and number of new coronary lesions among the three genotypes in the whole population at follow-up angiography (all $p>0.05$ ) (Table 3). In non- diabetic patients, risk $\mathrm{C}$ allele of rs1333049 was related to degree of MLD reduction $(0.25 \pm 0.49 \mathrm{~mm}$ for CC genotype, $0.20 \pm 0.35 \mathrm{~mm}$ for GC genotype, and $0.05 \pm$ $0.35 \mathrm{~mm}$ for GG genotype, respectively, $p=0.005$ ) (Table 4). Similar findings were observed for change of percent diameter stenosis, coronary artery score and cumulative coronary obstruction $(p=0.038,0.004$ and 0.025 , respectively). Although diabetic patients had more severe plaque progression than non-diabetic counterparts, no relations existed between plaque progression and genotypes (all $p>0.05$ ) (Table 4 ).

\section{Determinants of plaque progression}

Multivariable logistic regression analysis revealed that gender (male), hypertension, genotypes carrying allele $\mathrm{C}$, low HDL-C and high hsCRP were independently associated with plaque progression in non-diabetic patients during 1year follow-up (OR 3.468 95\% CI 1.504-8.000, $p=0.004$ for GC genotype and OR 4.339 95\% CI 1.740-10.821, $p=$ 0.002 for CC genotype). Meanwhile, gender (male), age, hyperlipidemia, smoking and high hsCRP, but not risk genotype of rs1333049, were independent determinants of plaque progression in diabetic patients (Table 5).

\section{Discussion}

This study demonstrates that SNP of rs1333049 on chromosome 9p21.3 increases the susceptibility to CAD in Chinese Han population and confers a magnified risk of coronary plaque progression in non-diabetic patients.

Several genome-wide association studies have shown that different genetic variations on chromosome 9p21.3 were associated with increased risk of diabetes, CAD and sudden cardiac death in the general population [2,8-10]. As one of the risk equivalents of CAD, diabetes increased atherosclerotic burden and inflammatory process in the coronary artery tree [12-14]. Doria et al reported an interaction between poor glycemic control and 9p21 locus on risk of CAD in type 2 diabetes [8]. However, we observed that homozygous CC genotype of rs 1333049 was not strongly associated with CAD in diabetic population in this study, which was in accordance with the findings from a prospective meta-analysis that no interaction existed between diabetes and rs1333049 polymorphism in CAD development [7]. Similarly, there was a magnified risk of $\mathrm{C}$ allele for coronary plaque progression in nondiabetic but not in diabetic patients, implying that polymorphism on chromosome 9p21 might have effects on CAD development in a novel biological pathway other than interaction with diabetes or glucose metabolism.

Genetic variation on chromosome $9 \mathrm{p} 21$ has been reported to be associated with progression of carotid but not coronary atherosclerosis in Caucasian population $[15,21]$. Besides, specific polymorphisms in the chromosome 9p21.3 region that were shown to be associated 
Table 1 Baseline clinical characteristics and biochemical assessments of plaque progression study

\begin{tabular}{|c|c|c|c|}
\hline & \multicolumn{3}{|c|}{ CAD } \\
\hline & $\begin{array}{l}\text { Plaque Progression } \\
(\mathrm{n}=137)\end{array}$ & $\begin{array}{l}\text { No Plaque Progression } \\
(\mathrm{n}=293)\end{array}$ & $P$ \\
\hline Men/Female (n) & $97 / 40$ & $208 / 85$ & 0.864 \\
\hline Age (years) & $64.13 \pm 7.80$ & $65.51 \pm 10.13$ & 0.299 \\
\hline Cigarette smoking (\%) & $61(44.5 \%)$ & $139(47.4 \%)$ & 0.604 \\
\hline Hypertension (\%) & $65(47.4 \%)$ & $130(44.4 \%)$ & 0.512 \\
\hline Hyperlipidemia (\%) & $36(26.3 \%)$ & $65(22.1 \%)$ & 0.466 \\
\hline Diabetes (\%) & $69(43.0 \%)$ & $81(28.0 \%)$ & 0.033 \\
\hline $\mathrm{BMI}\left(\mathrm{kg} / \mathrm{m}^{2}\right)$ & $24.63 \pm 3.46$ & $24.05 \pm 3.24$ & 0.189 \\
\hline Fasting plasma glucose (mmol/L) & $5.49 \pm 1.88$ & $5.99 \pm 2.00$ & 0.255 \\
\hline $2 \mathrm{~h}$ plasma glucose (mmol/L) & $13.40 \pm 4.20$ & $11.29 \pm 3.66$ & 0.039 \\
\hline $\mathrm{HbA}_{1 \mathrm{c}}(\%)$ & $6.79 \pm 1.48$ & $6.64 \pm 1.43$ & 0.315 \\
\hline $\mathrm{hsCRP}(\mathrm{mg} / \mathrm{ml})$ & $19.35 \pm 13.63$ & $11.87 \pm 9.22$ & $<0.001$ \\
\hline Total cholesterol (mmol/L) & $4.77 \pm 1.04$ & $4.84 \pm 1.16$ & 0.631 \\
\hline Triglyceride $(\mathrm{mmol} / \mathrm{L})$ & $1.93 \pm 1.53$ & $2.02 \pm 1.32$ & 0.319 \\
\hline LDL-C (mmol/L) & $2.80 \pm 0.79$ & $2.84 \pm 0.85$ & 0.672 \\
\hline $\mathrm{HDL}-\mathrm{C}(\mathrm{mmol} / \mathrm{L})$ & $1.09 \pm 0.31$ & $1.27 \pm 0.27$ & 0.015 \\
\hline apoA (g/L) & $1.22 \pm 0.20$ & $1.27 \pm 0.22$ & 0.156 \\
\hline apoB (g/L) & $0.97 \pm 0.22$ & $0.95 \pm 0.23$ & 0.674 \\
\hline Lipoprotein (a) (g/L) & $0.25 \pm 0.18$ & $0.23 \pm 0.16$ & 0.422 \\
\hline BUN (mmol/L) & $5.49 \pm 1.89$ & $5.88 \pm 1.65$ & 0.078 \\
\hline creatinine (mg/L) & $91.51 \pm 23.16$ & $89.78 \pm 20.08$ & 0.534 \\
\hline Statin (\%) & $126(92.1 \%)$ & $262(89.5 \%)$ & 0.475 \\
\hline ACEI or ARB (\%) & $114(83.3 \%)$ & $231(79.0 \%)$ & 0.285 \\
\hline$\beta$-blocker (\%) & $59(43.1 \%)$ & $121(50.9 \%)$ & 0.448 \\
\hline Antiplatelet (\%) & $123(90.1 \%)$ & 215 (90.3\%) & 0.656 \\
\hline Insulin (\%) & $36(26.2 \%)$ & $30(12.7 \%)$ & 0.069 \\
\hline Oral anti-diabetic drugs (\%) & $49(35.7 \%)$ & $111(46.5 \%)$ & 0.144 \\
\hline
\end{tabular}

Data are number (\%) and mean \pm SD;

Abbreviations: CAD, coronary artery disease; BMl, body mass index; HbA1c, glycosylated hemoglobin; hsCRP, high sensitivity C-reactive protein; HDL-C, highdensity lipoprotein cholesterol; LDL-C, low-density lipoprotein cholesterol; BUN, blood urea nitrogen.

with CAD in genome-wide analyses might not be related to clinical and angiographic outcomes after implantation of drug-eluting stents in the coronary arteries [22]. Thus, this study was the first to show an association of SNP on chromosome 9p21.3 with CAD and angiographic plaque progression in a special population. In addition, variant at chromosome 9p21 was associated with recurrent myocardial infarction and cardiac death after acute coronary syndrome, serving as a predictive factor of perioperative myocardial injury after coronary artery bypass graft surgery $[23,24]$. Taken together, this genetic factor might partially increase the risk of CAD by promoting atherosclerosis development or plaque instability.

The high risk of haplotype at $9 \mathrm{p} 21.3$ was shown to overlap with exons 13 to 19 of ANRIL [25-28], which was expressed in atheromatous plaques and served as a

Table 2 Multivariable analysis of independent determinants for coronary artery disease in the whole population

\begin{tabular}{|c|c|c|c|c|}
\hline Variables & Unadjusted OR $(95 \% \mathrm{Cl})$ & $p$ & Adjusted OR (95\% CI) & $p$ \\
\hline$\overline{R s 1333049 \text { (GC vs. GG) }}$ & $1.199(0.966-1.487)$ & 0.099 & $1.105(0.755-1.619)$ & 0.607 \\
\hline Rs1333049 (CC vs. GG) & $1.524(1.192-1.949)$ & 0.001 & $1.859(1.212-2.852)$ & 0.005 \\
\hline Gender (male vs. female) & $2.534(2.132-3.011)$ & $<0.001$ & $2.516(2.107-3.224)$ & $<0.001$ \\
\hline Age (years) & $2.093(1.760-2.489)$ & $<0.001$ & $1.952(1.627-2.341)$ & $<0.001$ \\
\hline Hypertension (yes vs. no) & $1.589(1.347-1.875)$ & $<0.001$ & $1.490(1.251-1.774)$ & $<0.001$ \\
\hline Hyperlipidemia (yes vs. no) & $1.187(0.952-1.473)$ & 0.119 & $1.274(1.008-1.608)$ & 0.042 \\
\hline Smoking (yes vs. no) & $2.242(1.893-2.655)$ & $<0.001$ & $1.837(1.527-2.211)$ & $<0.001$ \\
\hline Diabetes (yes vs. no) & $1.873(1.571-2.233)$ & $<0.001$ & $1.780(1.470-2.157)$ & $<0.001$ \\
\hline
\end{tabular}

Risk factors which are adjusted include gender, age, hypertension, hyperlipidemia, smoking status and diabetes. 
Table 3 Changes in biochemical and angiographic measurements during follow-up

\begin{tabular}{|c|c|c|c|c|}
\hline & \multicolumn{3}{|c|}{ Rs1333049 } & \multirow[b]{2}{*}{$p$} \\
\hline & GG $(n=122)$ & $G C(n=200)$ & $C C(n=108)$ & \\
\hline \multicolumn{5}{|l|}{ Change of Biochemical measurements } \\
\hline Total cholesterol $(\mathrm{mmol} / \mathrm{L})$ & $0.64 \pm 1.17$ & $0.41 \pm 1.12$ & $0.53 \pm 1.14$ & 0.228 \\
\hline LDL-C (mmol/L) & $0.27 \pm 0.98$ & $0.24 \pm 0.90$ & $0.34 \pm 0.86$ & 0.623 \\
\hline $\mathrm{HDL}-\mathrm{C}(\mathrm{mmol} / \mathrm{L})$ & $-0.05 \pm 0.49$ & $-0.01 \pm 0.22$ & $0.01 \pm 0.19^{\mathrm{a}}$ & 0.422 \\
\hline Triglyceride (mmol/L) & $0.41 \pm 1.92$ & $0.10 \pm 0.86^{\mathrm{a}}$ & $0.16 \pm 1.06^{\mathrm{b}}$ & 0.106 \\
\hline apoA (g/L) & $0.10 \pm 0.15$ & $0.09 \pm 0.17$ & $0.08 \pm 0.16$ & 0.029 \\
\hline apoB (g/L) & $0.41 \pm 0.37$ & $0.39 \pm 0.30$ & $0.40 \pm 0.34$ & 0.639 \\
\hline Lipoprotein (a) (g/L) & $-0.01 \pm 0.08$ & $-0.02 \pm 0.09$ & $-0.01 \pm 0.12$ & 0.873 \\
\hline Fast glucose (mmol/L) & $0.39 \pm 1.22$ & $0.42 \pm 2.48$ & $0.66 \pm 1.58$ & 0.487 \\
\hline $\mathrm{HbA}_{1 \mathrm{c}}(\%)$ & $0.52 \pm 1.54$ & $0.40 \pm 1.32$ & $0.27 \pm 1.44$ & 0.419 \\
\hline White blood cells $\left(\times 10^{9} / \mathrm{L}\right)$ & $0.75 \pm 2.02$ & $0.92 \pm 1.94^{\mathrm{a}}$ & $1.46 \pm 1.87^{\mathrm{a}}$ & 0.012 \\
\hline Neutrophile $\left(\times 10^{9} / \mathrm{L}\right)$ & $0.51 \pm 1.64$ & $0.66 \pm 1.98$ & $1.13 \pm 1.80^{\mathrm{a}}$ & 0.025 \\
\hline Lymphocyte (× $\left.10^{9} / \mathrm{L}\right)$ & $0.21 \pm 0.66$ & $0.21 \pm 0.64$ & $0.29 \pm 0.54$ & 0.463 \\
\hline \multicolumn{5}{|l|}{ Smoking status } \\
\hline Non-smoker (\%) & 67 (54.9\%) & $109(54.5 \%)$ & $54(49.2 \%)$ & 0.309 \\
\hline Smoker with cessation (\%) & $30(24.6 \%)$ & 49 (24.5\%) & $30(27.7 \%)$ & 0.474 \\
\hline Smoker without cessation (\%) & $25(20.5 \%)$ & $42(21.0 \%)$ & $24(23.1 \%)$ & 0.532 \\
\hline \multicolumn{5}{|l|}{ Angiographic features } \\
\hline New coronary lesion & $0.09 \pm 0.29$ & $0.07 \pm 0.26$ & $0.11 \pm 0.32$ & 0.385 \\
\hline Change of MLD (mm) & $0.18 \pm 0.46$ & $0.26 \pm 0.44$ & $0.29 \pm 0.50$ & 0.151 \\
\hline Change of diameter stenosis (\%) & $-5.14 \pm 15.87$ & $-8.82 \pm 16.03$ & $-9.38 \pm 14.89$ & 0.081 \\
\hline Coronary artery score (mm) & $0.05 \pm 0.03$ & $0.16 \pm 0.07$ & $0.21 \pm 0.11$ & 0.188 \\
\hline Cumulative coronary obstruction & $-0.03 \pm 0.09$ & $-0.20 \pm 0.13$ & $-0.31 \pm 0.21$ & 0.076 \\
\hline
\end{tabular}

MLD, minimal lumen diameter; other abbreviations are listed in table 1

a $<0.05$ compared with GG

b $<0.01$ compared with GG

Table 4 Plaque progression in different genotypes of rs1333049

\begin{tabular}{|c|c|c|c|c|}
\hline Non-DM $(\mathrm{N}=280)$ & GG $(n=90)$ & GC $(n=114)$ & CC $(n=76)$ & $p$ \\
\hline New coronary lesion & $0.05 \pm 0.22$ & $0.07 \pm 0.27$ & $0.11 \pm 0.32$ & 0.347 \\
\hline Change of MLD (mm) & $0.05 \pm 0.35$ & $0.20 \pm 0.35^{\mathrm{a}}$ & $0.25 \pm 0.49^{b}$ & 0.005 \\
\hline Change of diameter stenosis (\%) & $-3.44 \pm 13.80$ & $-7.38 \pm 13.70$ & $-8.93 \pm 14.64^{\mathrm{a}}$ & 0.038 \\
\hline Coronary artery score $(\mathrm{mm})$ & $0.01 \pm 0.02$ & $0.12 \pm 0.04^{a}$ & $0.16 \pm 0.07^{b}$ & 0.004 \\
\hline Cumulative coronary obstruction & $-0.02 \pm 0.11$ & $-0.17 \pm 0.09$ & $-0.28 \pm 0.13^{a}$ & 0.025 \\
\hline $\mathrm{DM}(\mathrm{N}=150)$ & $G G(n=32)$ & $\mathrm{GC}(n=86)$ & CC $(n=32)$ & \\
\hline New coronary lesion & $0.19 \pm 0.40$ & $0.07 \pm 0.23$ & $0.13 \pm 0.34$ & 0.173 \\
\hline Change of MLD (mm) & $0.34 \pm 0.53$ & $0.39 \pm 0.53$ & $0.46 \pm 0.56$ & 0.513 \\
\hline Change of diameter stenosis (\%) & $-9.20 \pm 19.61$ & $-10.86 \pm 18.77$ & $-10.67 \pm 15.74$ & 0.908 \\
\hline Coronary artery score $(\mathrm{mm})$ & $0.14 \pm 0.07$ & $0.22 \pm 0.11$ & $0.29 \pm 0.15$ & 0.152 \\
\hline Cumulative coronary obstruction & $-0.05 \pm 0.10$ & $-0.25 \pm 0.18$ & $-0.36 \pm 0.27$ & 0.770 \\
\hline
\end{tabular}

$M L D$, minimal lumen diameter.

a $<0.05$ compared with GG

b $<0.01$ compared with GG 
Table 5 Multivariable logistic regression analysis of independent determinants for plaque progression

\begin{tabular}{|c|c|c|c|c|c|c|c|}
\hline & HR & $95 \% \mathrm{Cl}$ & $p$ & & HR & $95 \% \mathrm{Cl}$ & $p$ \\
\hline Non-diabetes & & & & Diabetes & & & \\
\hline rs1333049 (GC vs. GG) & 3.468 & $1.504-8.000$ & 0.004 & & 0.529 & $0.685-1.474$ & 0.077 \\
\hline rs1333049 (CC vs. GG) & 4.339 & $1.740-10.821$ & 0.002 & & 0.878 & $0.278-2.814$ & 0.644 \\
\hline Gender (male vs. female) & 2.912 & $1.184-7.161$ & 0.020 & & 1.807 & $1.615-3.100$ & 0.007 \\
\hline Age $(y)$ & 0.993 & $0.914-1.025$ & 0.051 & & 0.932 & $0.876-0.995$ & 0.027 \\
\hline Hypertension & 2.129 & $1.066-4.251$ & 0.032 & & 2.287 & $0.840-6.223$ & 0.105 \\
\hline Hyperlipidemia & 2.110 & $0.732-4.148$ & 0.324 & & 6.057 & $1.922-22.145$ & 0.003 \\
\hline Smoking & 1.301 & $0.638-2.656$ & 0.469 & & 3.165 & $1.008-9.938$ & 0.048 \\
\hline Triglyceride & 0.880 & $0.601-1.298$ & 0.886 & & 1.130 & $0.580-2.119$ & 0.720 \\
\hline Total cholesterol & 0.531 & $0.247-1.429$ & 0.528 & & 0.431 & $0.254-1.116$ & 0.077 \\
\hline LDL-C & 1.422 & $0.497-2.104$ & 0.701 & & 1.749 & $0.556-2.599$ & 0.378 \\
\hline $\mathrm{HDL}-\mathrm{C}$ & 0.471 & $0.106-0.877$ & 0.030 & & 0.214 & $0.005-0.915$ & 0.037 \\
\hline Creatinine & 1.104 & $0.975-1.156$ & 0.226 & & 1.009 & $0.989-1.029$ & 0.361 \\
\hline Baseline hsCRP & 1.302 & $1.115-1.522$ & $<0.001$ & & 1.283 & $1.211-1.309$ & $<0.001$ \\
\hline Use of statins & 1.401 & $0.644-3.492$ & 0.562 & & 1.709 & $0.590-4.952$ & 0.317 \\
\hline BMI & 1.028 & $0.925-1.143$ & 0.608 & & 1.025 & $0.889-1.181$ & 0.734 \\
\hline
\end{tabular}

Abbreviations are as in Table 1.

functional enhancer of cellular proliferation and inflammation [25,27]. And, variants on 9p21.3 had a role in regulation of cardiac cyclin dependent kinase inhibitor $2 \mathrm{~A} / 2 \mathrm{~B}$ (CDKN2A/2B) expression by altering the dynamics of vascular cell proliferation [29]. As white blood cells especially neutrophiles, an important cell line in vascular inflammation, were significantly increased in CC genotype carriers in this study, the relationship between 9 p21.3 and inflammation might be a possible explanation for angiographic plaque progression. Further functional analyses are needed to clarify possible pathways in which this SNP on chromosome 9p21.3 contributes to development of $\mathrm{CAD}$ and plaque progression.

Although diabetic patients had more severe plaque progression than non-diabetic counterparts, risk genotype of rs1333049 was not an independent determinant of plaque progression in diabetes. The difference in association between variant rs1333049 on chromosome 9p21.3 and plaque progression in diabetic and non-diabetic patients suggested that CAD in diabetes might be mediated through a pathway other than polymorphism on 9 p21.3, and perhaps the role of other risk factors exceeded that of variants on $9 \mathrm{p} 21.3$ in conferring more severe plaque burden for diabetic patients.

This study had several limitations. First, all patients received medical treatments during follow-up, which could affect the natural course of the disease and plaque progression. However, since patients with or without plaque progression received similar medical treatment which was listed in Table 1 and no significant change of medical treatment was made before the result of the follow-up angiography, these could help to decrease the influence of treatment to certain extent. Second, case- control studies had advantages for identifying disease related genes, but they were limited to detect geneenvironment interactions [30]. A prospective cohort study is needed to better illustrate the role of genetic and environmental factors as well as their interactions in CAD development.

\section{Conclusions}

Polymorphism on chromosome $9 \mathrm{p} 21.3$ is significantly associated with CAD in Chinese Han population, and also contributes to coronary plaque progression in nondiabetic patients. Thus, SNP scanning on 9p21.3 should been done to select the patients with potential risk of $\mathrm{CAD}$ or angiographic plaque progression in non-diabetic population. Early medical intervention or close followup of non-diabetic patients with risk genotype is of equal importance to primary or secondary prevention for CAD in diabetes.

\section{Acknowledgements}

This study was supported by a grant from Shanghai High-Tech Foundation.

\section{Author details}

'Department of Cardiology, Rui Jin Hospital, Shanghai Jiaotong University School of Medicine, Shanghai 200025, People's Republic of China. ${ }^{2}$ Institute of Cardiovascular Diseases, Shanghai Jiaotong University School of Medicine, Shanghai 200025, People's Republic of China.

\section{Authors' contributions}

WW, WP, XZ, LW and QC carried out the molecular genetic studies and DNA extraction, participated in the sequence alignment, genotyping study and drafted the manuscript. WW, LL, RZ and QZ participated in the design of the study and performed the statistical analysis. WS conceived of the study, and participated in its design and coordination. All authors read and approved the final manuscript. 


\section{Competing interests}

The authors declare that they have no competing interests.

Received: 2 July 2010 Accepted: 6 August 2010

Published: 6 August 2010

\section{References}

1. Consortium WTCC: Genome-wide association study of 14,000 cases of seven common diseases and 3,000 shared controls. Nature 2007, 447(7145):661-678

2. Newton-Cheh C, Cook NR, VanDenburgh M, Rimm EB, Ridker PM, Albert CM: A common variant at 9 p21 is associated with sudden and arrhythmic cardiac death. Circulation 2009, 120(21):2062-2068.

3. Samani NJ, Erdmann J, Hall AS, Hengstenberg C, Mangino M, Mayer B, Dixon RJ, Meitinger T, Braund P, Wichmann HE, Barrett JH, Konig IR, Stevens SE, Szymczak S, Tregouet DA, lles MM, Pahlke F, Pollard H, Lieb W, Cambien F, Fischer M, Ouwehand W, Blankenberg S, Balmforth AJ, Baessler A, Ball SG, Strom TM, Braenne I, Gieger C, Deloukas P, Tobin MD, Ziegler A, Thompson JR, Schunkert H: Genomewide association analysis of coronary artery disease. N Engl J Med 2007, 357(5):443-453.

4. Wang Q: Molecular genetics of coronary artery disease. Curr Opin Cardiol 2005, 20(3):182-188.

5. McPherson R: Chromosome 9p21 and coronary artery disease. N Engl J Med 2010, 362(18):1736-1737.

6. Palomaki GE, Melillo S, Bradley LA: Association between 9p21 genomic markers and heart disease: a meta-analysis. JAMA 2010, 303(7):648-656.

7. Shunkert H, Gotz A, Braund P, McGinnis R, Tregouet DA, Mangino M, LinselNitschke P, Cambien F, Hengstenberg C, Stark K, Blankenberg S, Tiret L, Ducimetiere P, Keniry A, Ghori MJ, Schreiber S, El Mokhtari NE, Hall AS, Dixon RJ, Goodall AH, Liptau H, Pollard H, Schwarz DF, Hothorn LA, Wichmann HE, Konig IR, Fischer M, Meisinger C, Ouwehand W, Deloukas P, Thompson JR, Erdmann J, Ziegler A, Samani NJ: Repeated replication and a prospective meta-analysis of the association between chromosome 9p21.3 and coronary artery disease. Circulation 2008, 117(13):1675-1684.

8. Doria A, Wojcik J, Xu R, Gervino EV, Hauser TH, Johnstone MT, Nolan D, $\mathrm{Hu} F \mathrm{FB}$, Warram JH: Interaction between poor glycemic control and 9p21 locus on risk of coronary artery disease in type 2 diabetes. JAMA 2008, 300(20):2389-2397.

9. Schunkert H, Gotz A, Braund P, McGinnis R, Tregouet DA, Mangino M, Linsel-Nitschke P, Cambien F, Hengstenberg C, Stark K, Blankenberg S, Tiret L, Ducimetiere P, Keniry A, Ghori MJ, Schreiber S, El Mokhtari NE, Hall AS, Dixon RJ, Goodall AH, Liptau H, Pollard H, Schwarz DF, Hothorn LA, Wichmann HE, Konig IR, Fischer M, Meisinger C, Ouwehand W, Deloukas P, Thompson JR, Erdmann J, Ziegler A, Samani NJ: Coronary artery diseaseassociated locus on chromosome 9p21 and early markers of atherosclerosis. Arterioscler Thromb Vasc Biol 2008, 28(9):1679-1683.

10. Silander K, Tang H, Myles S, Jakkula E, Timpson NJ, Cavalli-Sforza L, Peltonen $L$ : Worldwide patterns of haplotype diversity at 9p21.3, a locus associated with type 2 diabetes and coronary heart disease. Genome Med 2009, 1(5):51.

11. Gori F, Specchia C, Pietri S, Crociati L, Barlera S, Franciosi M, Nicolucci A, Signorini S, Brambilla P, Franzosi MG: Common genetic variants on chromosome 9p21 are associated with myocardial infarction and type 2 diabetes in an Italian population. BMC Med Genet 2010, 11:60.

12. Aronson D, Rayfield EJ: How hyperglycemia promotes atherosclerosis: molecular mechanisms. Cardiovasc Diabetol 2002, 1:1.

13. Pu L, Lu L, Xu XW, Zhang RY, Zhang Q, Zhang JS, Hu J, Yang ZK, Ding FH, Chen QJ, Lou S, Shen J, Fang DH, Shen WF: Value of serum glycated albumin and high-sensitivity C-reactive protein levels in the prediction of presence of coronary artery disease in patients with type 2 diabetes. Cardiovasc Diabetol 2006, 5:27.

14. Andersson C, Gislason GH, Weeke P, Hoffmann S, Hansen PR, TorpPedersen C, Sogaard P: Diabetes is associated with impaired myocardial performance in patients without significant coronary artery disease. Cardiovasc Diabetol 2010, 9:3.

15. Chen SN, Ballantyne CM, Gotto AM Jr, Marian AJ: The 9p21 susceptibility locus for coronary artery disease and the severity of coronary atherosclerosis. BMC Cardiovasc Disord 2009, 9:3.

16. Peng WH, Lu L, Hu J, Yan XX, Zhang Q, Zhang RY, Chen QJ, Shen WF: Decreased serum esRAGE level is associated with angiographically determined coronary plaque progression in diabetic patients. Clin Biochem 2009, 42(12):1252-1259.

17. Zheng JL, Lu L, Hu J, Zhang RY, Zhang Q, Chen QJ, Shen WF: Increased serum YKL-40 and C-reactive protein levels are associated with angiographic lesion progression in patients with coronary artery disease. Atherosclerosis 2009, 210(2):590-595.

18. Lansky AJ, Desai K, Leon MB: Quantitative coronary angiography in regression trials: a review of methodologic considerations, endpoint selection, and limitations. Am J Cardiol 2002, 89(4A):4B-9B.

19. Berry C, L'Allier PL, Gregoire J, Lesperance J, Levesque S, Ibrahim R, Tardif JC: Comparison of intravascular ultrasound and quantitative coronary angiography for the assessment of coronary artery disease progression. Circulation 2007, 115(14):1851-1857.

20. Peng WH, Lu L, Zhang Q, Zhang RY, Wang L, Yan XX, Chen QJ, Shen WF: Chromosome 9p21 polymorphism is associated with myocardial infarction but not with clinical outcome in Han Chinese. Clin Chem Lab Med 2009, 47(8):917-922.

21. Ye S, Willeit J, Kronenberg F, Xu Q, Kiechl S: Association of genetic variation on chromosome $9 \mathrm{p} 21$ with susceptibility and progression of atherosclerosis: a population-based, prospective study. Journal of the American College of Cardiology 2008, 52(5):378-384.

22. Hoppmann P, Erl A, Turk S, Tiroch K, Mehilli J, Schomig A, Kastrati A Koch W: No association of chromosome 9p21.3 variation with clinical and angiographic outcomes after placement of drug-eluting stents. JACC Cardiovasc Interv 2009, 2(11):1149-1155.

23. Buysschaert I, Carruthers KF, Dunbar DR, Peuteman G, Rietzschel E, Belmans A, Hedley A, De Meyer T, Budaj A, Van de Werf F, Lambrechts D, Fox KA: A variant at chromosome 9 p21 is associated with recurrent myocardial infarction and cardiac death after acute coronary syndrome: The GRACE Genetics Study. Eur Heart J 2010, 31(9):1132-1141.

24. Liu KY, Muehlschlegel JD, Perry TE, Fox AA, Collard CD, Body SC, Shernan SK: Common genetic variants on chromosome 9p21 predict perioperative myocardial injury after coronary artery bypass graft surgery. J Thorac Cardiovasc Surg 2010, 139(2):483-488, 488 e481-482.

25. Broadbent HM, Peden JF, Lorkowski S, Goel A, Ongen H, Green F, Clarke R, Collins R, Franzosi MG, Tognoni G, Seedorf U, Rust S, Eriksson P, Hamsten A, Farrall $\mathrm{M}$, Watkins $\mathrm{H}$ : Susceptibility to coronary artery disease and diabetes is encoded by distinct, tightly linked SNPs in the ANRIL locus on chromosome 9p. Human molecular genetics 2008, 17(6):806-814.

26. Holdt LM, Beutner F, Scholz M, Gielen S, Gabel G, Bergert H, Schuler G, Thiery J, Teupser D: ANRIL Expression Is Associated With Atherosclerosis Risk at Chromosome 9p21. Arterioscler Thromb Vasc Biol 2010, 30(3):620-627.

27. Jarinova O, Stewart AF, Roberts R, Wells G, Lau P, Naing T, Buerki C, McLean BW, Cook RC, Parker JS, McPherson R: Functional Analysis of the Chromosome 9p21.3 Coronary Artery Disease Risk Locus. Arterioscler Thromb Vasc Biol 2009, 29(10):1671-1677.

28. Cunnington MS, Santibanez Koref M, Mayosi BM, Burn J, Keavney B: Chromosome 9p21 SNPs Associated with Multiple Disease Phenotypes Correlate with ANRIL Expression. PLoS Genet 2010, 6(4):e1000899.

29. Visel A, Zhu Y, May D, Afzal V, Gong E, Attanasio C, Blow MJ, Cohen JC, Rubin EM, Pennacchio LA: Targeted deletion of the 9p21 non-coding coronary artery disease risk interval in mice. Nature 2010, 464(7287):409-412

30. Manolio TA, Bailey-Wilson JE, Collins FS: Genes, environment and the value of prospective cohort studies. Nat Rev Genet 2006, 7(10):812-820.

doi:10.1186/1475-2840-9-33

Cite this article as: Wang et al: Chromosome 9p21.3 polymorphism in a Chinese Han population is associated with angiographic coronary plaque progression in non-diabetic but not in type 2 diabetic patients. Cardiovascular Diabetology 2010 9:33. 